\title{
PROTEOLYTIC ACTIVITY OF 26S PROTEASOMES ISOLATED FROM MUSCLES OF THE TOBACCO HORNWORM, MANDUCA SEXTA: DIFFERENCES BETWEEN SURVIVING MUSCLES AND THOSE UNDERGOING DEVELOPMENTALLY PROGRAMMED CELL DEATH*
}

\author{
P. Löw, ${ }^{1 * *}$ S. E. REYNOLDS ${ }^{2}$ and M. SASS ${ }^{1}$ \\ ${ }^{1}$ Department of General Zoology, Eötvös Loránd University, P.O. Box 330, H-1445 Budapest, Hungary \\ ${ }^{2}$ School of Biology and Biochemistry, University of Bath, Bath, U.K. \\ (Received: January 10, 2001; accepted: March 2, 2001)
}

\begin{abstract}
The intersegmental muscles (ISMs) of tobacco hornworm, Manduca sexta are a well-characterised model system for examining the biochemical changes that accompany programmed cell death during development. When the ISMs become committed to die, there are dramatic increases in both the ubiquitinexpression, and ubiquitin-dependent proteolysis. Since the $26 \mathrm{~S}$ proteasome is responsible for ATP/ubiquitin-dependent proteolysis in cells, we examined its enzymatic properties. Specific chymotrypsin-like proteolytic activity of $26 \mathrm{~S}$ proteasomes isolated from ISM is four times higher than that of surviving flight muscle (FM). However, specific activity does not change between developmental stages within ISM or FM. The difference between proteolytic capacity of the two kinds of muscles is even higher when the ISM become committed to die because $26 \mathrm{~S}$ proteasome content of ISM increases just before cell death. These observations underline the role of $26 \mathrm{~S}$ proteasome in programmed cell death.
\end{abstract}

Keywords: Manduca sexta - 26S proteasome - enzyme activity - intersegmental muscle - flight muscle

\section{INTRODUCTION}

Metamorphosis in insects is one of the most dramatic developmental processes involving programmed cell death (PCD), cell proliferation and differentiation. The intersegmental muscles (ISMs) of the tobacco hornworm, Manduca sexta are a particularly useful model for examining the biochemical events mediating PCD. The ventral intersegmental muscles of abdominal segments 3-6, which are retained from the larval condition through the 3-week pupal stage, are used during the emergence (eclosion) of the adult moth from the pupal case, but then degenerate and die. The muscles begin to regress in the ca. $48 \mathrm{~h}$ period prior to eclosion, a change dependent on the pre-emergence decline in titre of the insect's ecdysteroid moulting hormone, 20 -hydroxyecdysone, and then abruptly regress during the ca. $36 \mathrm{~h}$ following eclo-

\footnotetext{
*Dedicated to Professor János Kovács on the occasion of his 70th birthday.

**Corresponding author; e-mail: peterlow@cerberus.elte.hu
} 
sion $[9,14]$. In contrast thoracic flight muscles (FM) and other organs develop in preparation for adult flight.

Muscle proteins to be eliminated are labelled by ubiquitin and digested by a multicatalytic enzyme complex, the $26 \mathrm{~S}$ proteasome [10]. This proteolytic machine consists of a 20S proteasome core and two regulatory 19S 'caps', one at either end of that core. Two juxtaposed rings of $7 \beta$-type subunits flanked on both the top and bottom by a ring of $7 \alpha$-type subunits form the barrel-shaped $20 \mathrm{~S}$ core complex. Together, these four rings enclose three inner compartments, two antechambers and one central proteolytic chamber. Each regulatory 19S cap contains a 'base' and a 'lid' complex. The 'base' complex, which directly contacts an $\alpha$ type ring of the $20 \mathrm{~S}$ core, is currently thought to comprise all six ATPases ( $\mathrm{S} 4, \mathrm{~S} 6, \mathrm{~S} 6$ ', S7, S8, S10b), and the two largest subunits (S1, S2), as well as S5a, the ubiquitin binding subunit. The 'lid' complex consists of eight subunits and is necessary for degradation of ubiquitinated target proteins. Several functions have been proposed for the ATPases. The hydrolysis of ATP is supposed to promote the assembly of $26 \mathrm{~S}$ proteasomes. The ATPases could have a role in the gating of the translocation channel on the $20 \mathrm{~S}$ particle. Substrate proteins are possibly bound and unfolded by the ATPases. The ATPases might assist in the translocation of unfolded substrate proteins into the central proteolytic chamber of the $20 \mathrm{~S}$ proteasome [18]. Consistent with these proposals the 'base' complex of the 19S cap has recently been shown to have chaperone-like activity $[3,19]$.

Recent studies in Manduca sexta have emphasised the importance of the ubiquitin-dependent cytosolic protein degradation system in the elimination of ISMs, including an enormous increase in polyubiquitin gene expression [15], conjugation of ubiquitin to muscle proteins [7], changes in $20 \mathrm{~S}$ core subunits [8] and extensive reprogramming of the ATPase regulators of the $26 \mathrm{~S}$ proteasome [4]. However, there has as yet been no detailed study of the enzymatic properties of proteasomes of different tissues during development. We examined for the first time the enzyme kinetics of the 26S proteasome in ISM and FM in the period leading up to eclosion. The studies show that there are not only more proteasomes present in ISM but they digest ubiquitinated proteins at a higher rate during the elimination of ISM. These observations strengthen the role of $26 \mathrm{~S}$ proteasome in programmed cell death.

\section{MATERIALS AND METHODS}

\section{Insects}

Tobacco hornworms, Manduca sexta (L.) (Lepidoptera; Sphingidae) were reared at $25^{\circ} \mathrm{C}$, under a $17 \mathrm{~h}$ light $-7 \mathrm{~h}$ dark photoperiod, on a wheat germ-based artificial diet using standard procedures [1]. Different stages of pharate adult development were recognised by a staging scheme adapted from that of Schwartz and Truman [16] and described fully in [13]. Briefly, stages of development mentioned in this paper are as 
follows: pharate adult stage 0 : greater than $100 \mathrm{~h}$ before eclosion; pharate adult stage 7: about $6 \mathrm{~h}$ before eclosion.

\section{Separation of 26 S proteasomes on glycerol gradients and assay of peptidase activity}

Muscle samples taken from insects were dissected under a simple insect saline solution [6], immediately frozen on a metal surface cooled with liquid nitrogen, and kept at $-70{ }^{\circ} \mathrm{C}$ until needed. Soluble muscle extract ( $5 \mathrm{mg}$ protein) prepared from stage 0 and stage 7 ISM and FM were loaded onto a $14 \mathrm{ml} \mathrm{10-40 \%} \mathrm{(v/v)} \mathrm{glycerol} \mathrm{gradient}$ according to the method of Orino et al. [11]. Samples were centrifuged at 70,000 g in a SW $6 \times 15$ rotor for $22 \mathrm{~h}$. Fractions of $0.5 \mathrm{ml}$ were collected and assayed for chymotrypsin-like activity and protein. The chymotrypsin-like activity of the $26 \mathrm{~S}$ proteasomes were measured using the fluorogenic substrate Suc-LLVY-MCA (Peptide Institute, Inc., Osaka, Japan). Enzyme activity was assayed by incubating glycerol gradient fractions with $0.2 \mathrm{mM}$ substrate in $100 \mathrm{mM}$ Tris- $\mathrm{HCl}(\mathrm{pH} 7.5)$ for $20 \mathrm{~min}$ at $37{ }^{\circ} \mathrm{C}$ in a final volume of $105 \mu \mathrm{l}$. The reaction was stopped by the addition of 80 $\mathrm{mM}$ acetate $(\mathrm{pH} 4.5)$, and fluorescence was measured on a Perkin-Elmer LS 5B Luminescence Spectrometer at an excitation of $380 \mathrm{~nm}$ and an emission of $460 \mathrm{~nm}$. Protein was determined according to the method of Bradford [2].

\section{Enzyme kinetics}

Enzyme kinetical data were collected by incubating a constant amount of purified $26 \mathrm{~S}$ proteasome $(0.5 \mathrm{mg})$ from one of the glycerol gradient peaks at varying initial fluorogenic substrate concentration $\left(\mathrm{S}_{0}, 24.8-248 \mu \mathrm{M}\right.$ Suc-LLVY-MCA at seven points) in a reaction mix of $500 \mu 1$ of total volume containing $1 \mathrm{mM} \mathrm{ATP,} 2 \mathrm{mM}$ $\mathrm{MgCl}_{2}$ in $20 \mathrm{mM}$ Tris- $\mathrm{HCl}(\mathrm{pH} 8.0)$ for $1 \mathrm{~min}$ at $25^{\circ} \mathrm{C}$ while the initial rate $\left(\mathrm{v}_{0}\right)$ was registered on a recording spectrophotometer (Perkin-Elmer LS 5B). The acquired data showed that proteasomes with this substrate follow Michaelis kinetics then the Michaelis constant $\left(K_{\mathrm{m}}\right)$ and maximum velocity $(V)$ were calculated. The whole measurement was performed with every $26 \mathrm{~S}$ proteasome samples prepared from stage 0 and stage 7 ISM and stage 0 and stage 7 FM.

\section{RESULTS}

26S proteasomes were isolated from ISM and FM both at stage 0 and 7 by glycerol gradient centrifugation. Total muscle protein loaded on the gradient was the same ( 5 $\mathrm{mg}$ ) in all cases. Fractions were assayed for protein and chymotrypsin-like activity (Fig. 1). Total chymotrypsin-like activity increased in ISM from stage 0 to stage 7 by a factor of 7.9-times based on area under curve (Fig. 1A, B). However, protein con- 
A; ISM St 0

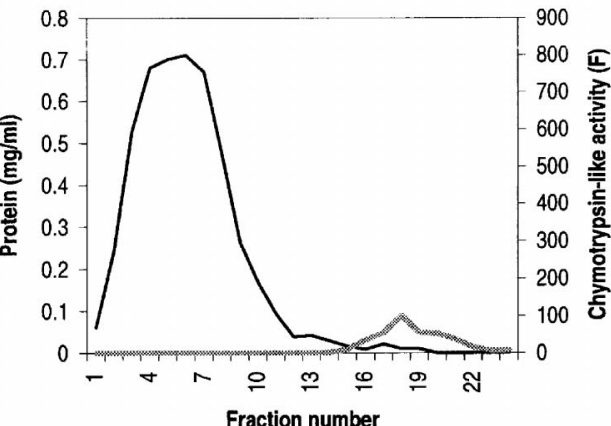

C; FM St 0

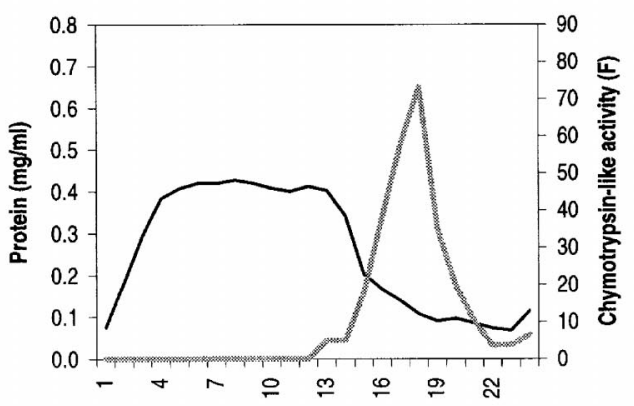

Fraction number
B; ISM St 7

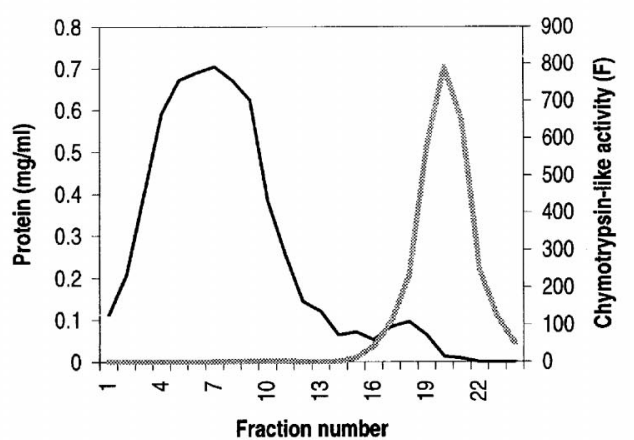

D; FM St 7

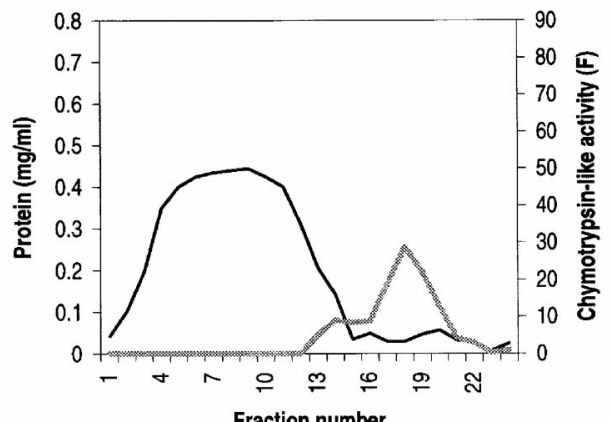

Fraction number

Fig. 1. Glycerol gradient preparation of $26 \mathrm{~S}$ proteasomes from intersegmental muscles (ISM) and flight muscles (FM) of Manduca sexta at developmental stage 0 and stage 7 . Soluble muscle extracts were fractionated on $10-40 \%$ glycerol gradients. Samples of each fraction were assayed for protein (black line) and chymotrypsin-like activities (grey line). Panels A, B, C and D show gradient analysis of proteasomes from ISM at stage 0 and stage 7 , and FM at stage 0 and stage 7 , respectively. The scale of chymotrypsin-like activities on panels A and B is 10-times higher than on panels C and D. F - fluorescent units 
tent was 6.1-times higher in stage 7 fraction of the enzyme activity peak. The overall activity was higher due to the fact that much more enzyme complex was present. Specific activity showed only a slight increase of 1.3-times from stage 0 to 7 . Total chymotrypsin-like activity seemed to decrease in FM from stage 0 to 7 by a factor of 2.4-times based on the area under curve (Fig. 1C, D). Nevertheless, this was accompanied by an even bigger drop $(3.2 \times)$ in protein content of the corresponding fractions. All in all the specific activity of 26S proteasomes in FM increased from stage 0 to stage 7 by 1.3 -fold. Comparing total as well as specific activities of $26 \mathrm{~S}$ proteasomes of the two tissue types the values for ISM were much higher at all stages (Fig. 1).

We decided to collect enzyme kinetical data to determine the difference between enzymatic properties of $26 \mathrm{~S}$ proteasomes of the two kinds of muscles. Data show that the purified 26S proteasomes of both muscles (ISM, FM) follow Michaelis kinetics

Table 1

Maximum velocity $(V)$ and Michaelis constant $\left(K_{\mathrm{m}}\right)$ values of proteasomes isolated from intersegmental muscles (ISM) and flight muscles (FM) of Manduca sexta at developmental stages 0 and 7 measured with the fluorogenic substrate Suc-LLVY-MCA

\begin{tabular}{lcc}
\hline & $V(\mathrm{nM} / \mathrm{min} / \mathrm{g})$ & $\mathrm{K}_{\mathrm{m}}(\mu \mathrm{M})$ \\
\hline ISM St $0(\mathrm{n}=5)$ & 57.2 & 84.6 \\
ISM St 7 $(\mathrm{n}=5)$ & 62.4 & 108.1 \\
FM St 0 $(\mathrm{n}=3)$ & 13.0 & 34.6 \\
FM St 7 $(\mathrm{n}=3)$ & 13.2 & 35.9 \\
\hline
\end{tabular}

$\mathrm{n}$ - number of independent isolations and activity assays of which the average value was calculated

in both stage 0 and stage 7 . There was no statistically significant difference in maximum velocity $(V)$ and Michaelis constant $\left(K_{\mathrm{m}}\right)$ values between stages 0 and 7 in either of the muscles $\left(V: \mathrm{F}=0.154, \mathrm{p}=0.701 ; K_{\mathrm{m}}: \mathrm{F}=0.194 ; \mathrm{p}=0.667\right)$, although values of stage 7 ISM were somewhat higher than those of stage 0 ISM (Table 1). However, there was a significant difference in the values between the muscle types $\left(V: \mathrm{F}=6.615, \mathrm{p}=0.023 ; K_{\mathrm{m}}: \mathrm{F}=7.670 ; \mathrm{p}=0.016\right)($ Table 1$)$. Initial rate $\left(\mathrm{v}_{0}\right)$ against fluorogenic substrate (Suc-LLVY-MCA) concentration $\left(\mathrm{S}_{0}\right)$ are plotted in Fig. 2 for proteasomes of the two tissue types using the average values of Table 1 (ISM: $\left.V=59.8 \mathrm{nM} / \mathrm{min} / \mathrm{g}, K_{\mathrm{m}}=96.4 \mu \mathrm{M} ; \mathrm{FM}: V=13.1 \mathrm{nM} / \mathrm{min} / \mathrm{g}, K_{\mathrm{m}}=35.2 \mu \mathrm{M}\right) .26 \mathrm{~S}$ proteasomes of dying ISM had 4-times higher maximum velocity $(V)$ and 3-times bigger Michaelis constant $\left(K_{\mathrm{m}}\right)$ (Table 1, Fig. 2$)$ at the constant enzyme concentration $(1 \mathrm{mg} / \mathrm{l})$ used. 


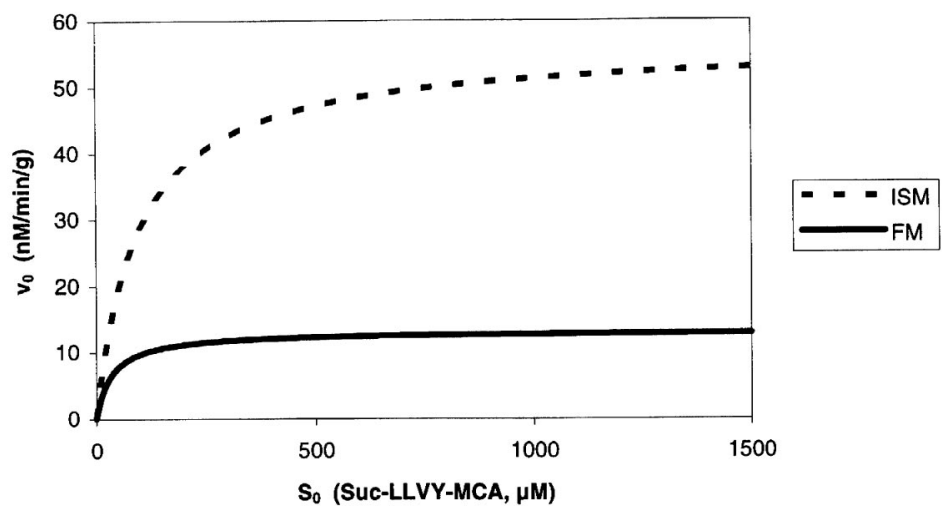

Fig. 2. Plot of initial rate $\left(\mathrm{v}_{0}\right)$ against fluorogenic substrate (Suc-LLVY-MCA) concentration $\left(\mathrm{S}_{0}\right)$ for proteasomes of intersegmental muscles (ISM, dashed line) and flight muscles (FM, solid line) of Manduca sexta. Curves were plotted using the average values of Table 1 (ISM: V $=59.8 \mathrm{nM} / \mathrm{min} / \mathrm{g}, K_{\mathrm{m}}=96.4 \mu \mathrm{M}$; FM: $\left.V=13.1 \mathrm{nM} / \mathrm{min} / \mathrm{g}, K_{\mathrm{m}}=35.2 \mu \mathrm{M}\right)$

\section{DISCUSSION}

We isolated 26S proteasomes from intersegmental muscles (ISM) and flight muscles (FM) of Manduca sexta and measured and compared the chymotrypsin-like proteolytic activities of these proteasomes before and after the commitment of ISM to undergo programmed cell death. The total activity increased from stage 0 to stage 7 in ISM while it was much lower and even decreased in FM (Fig. 1). Taking the protein content into account it turned out that the specific activity did not change from stage 0 to stage 7 in either tissue. However, the specific activity of proteasomes in ISM was four times higher than that of the FM (Table 1, Fig. 2).

The loss of the Manduca ISMs involves a massive proteolytic effort in order to remove these giant cells within $36 \mathrm{~h}$ at $26^{\circ} \mathrm{C}$. This is presumably why there is a higher level of proteasomes (compared to stage 0 or levels in FM) and these proteasomes are more active (compared to FM) in ISM at stage 7. There is an intensive restructuring of larval tissues in pupae of Holometabola insects which involves protein degradation as well as synthesis. The increased level of proteasomes in FM at stage 0 correlates very well with this process. At stage 7 in the developed FM we suppose that a lower level of proteasomes is sufficient to perform the normal housekeeping functions.

Several studies have examined the role of proteasomes in programmed cell death and the possible changes in its activity and subunit composition during the process (reviewed in $[5,12]$ ). Now it is generally accepted that the $26 \mathrm{~S}$ proteasome plays a major role in the programmed elimination of ISM in Manduca sexta. Some authors found changes in the subunit composition of the regulatory part and also the core particle (20S proteasome) during the cell death process $[4,8,17]$. They also observed a 
major increase in the proteolytic activity of the proteasome in the same time. We focused our studies on the enzymatic properties of the $26 \mathrm{~S}$ proteasome. However, according to our measurements although the total chymotrypsin-like activity increased the amount of proteasomes was also higher so the specific activity remained unchanged in ISM from stage 0 to stage 7 (Fig. 1A, B). Increased amount of or newly added cell death specific subunits may increase the activity of $26 \mathrm{~S}$ proteasomes in vivo on ubiquitinated target proteins.

We isolated intact $26 \mathrm{~S}$ proteasomes under conditions in which they remained intact. Regulatory subunits in $19 \mathrm{~S}$ particles are believed to recognise, bind, and unfold ubiquitinated proteins and translocate them into the proteolytic core [8]. For large proteins the enzymatically active centre of the complex is accessible only with the help of the regulatory part. However, small peptides can get into the central chamber without the involvement of other proteins [8]. In this work, a tetrapeptide with a fluorogenic moiety (Suc-LLVY-MCA) was used for measuring the chymotrypsin-like activity of the intact $26 \mathrm{~S}$ proteasome. This substrate is small enough to enter the enzyme's catalytic core bypassing the regulatory part of the proteasome. Thus we measured the proteolytic activity of the $20 \mathrm{~S}$ core of the proteasome itself rather than that of the whole $26 \mathrm{~S}$ complex. According to our data this intrinsic proteolytic activity does not change during the programmed cell death of ISM. But since we know from previous work that the regulatory subunits of the ISM proteasomes change at the time that programmed cell death is occurring [4], and that these regulatory subunits are likely to selectively control access of proteins to the enzymatically active core of the organelle, it is probable that the proteolysis of key muscle fibre proteins by $26 \mathrm{~S}$ proteasomes could still change even while core chymotryptic activity (as measured here) remained constant. The key finding of the present work is that differences in the kinetics of the intrinsic proteolytic (chymotryptic) activity of $26 \mathrm{~S}$ proteasomes between those muscles that are destined to die (ISM), and those that are destined to survive (FM). Thus there are probably key differences in the core subunit make-up of these organelles between the two types of muscle. The differences could reflect the increased need for intracellular proteolysis in ISM during programmed cell death. Studies described in this paper provide additional evidence that the ubiquitin-proteasome system plays a potentially important role in the events contributing to programmed cell death in the intersegmental muscles of Manduca sexta.

\section{ACKNOWLEDGEMENTS}

This work was supported by grants from The Wellcome Trust (042476) to P.L. and S.E.R. and from the Hungarian Scientific Research Fund (OTKA, T 029548) to M.S. P.L. is a holder of János Bolyai Research Fellowship (00173/98). 


\section{REFERENCES}

1. Bell, R. A., Joachim, F. A. (1976) Techniques for rearing laboratory colonies of tobacco hornworms and pink bollworms. Ann. Ent. Soc. Am. 69, 365-373.

2. Bradford, M. M. (1976) A rapid sensitive method for the quantitation of microgram quantities of protein using the principle of protein dye binding. Anal. Biochem. 71, 248-254.

3. Braun, B. C., Glickman, M., Kraft, R., Dahlmann, B., Kloetzel, P. M., Finley, D., Schmidt, M. (1999) The base of the proteasome regulatory particle exhibits chaperone-like activity. Nature Cell Biol 1, 221-226.

4. Dawson, S. P., Arnold, J. E., Mayer, N. J., Reynolds, S. E., Billett, M. A., Gordon, C., Colleaux, L., Kloetzel, P. M., Tanaka, K., Mayer, R. J. (1995) Developmental changes of the 26S proteasome in abdominal intersegmental muscles of Manduca sexta during programmed cell death. J. Biol. Chem. $270,1850-1858$.

5. Drexler, H. C. A. (1998) Programmed cell death and the proteasome. Apoptosis 3, 1-7.

6. Ephrussi, B., Beadle, A. W. (1936) A technique of transplantation for Drosophila. Am. Nat. 70, 218-225.

7. Haas, A. L., Baboshina, O., Williams, B., Schwartz, L. M. (1995) Co-ordinated induction of the ubiquitin conjugation pathway accompanies the developmentally programmed death of insect skeletal muscle. J. Biol. Chem. 270, 9407-9412.

8. Jones, M. E. E., Haire, M. F., Kloetzel, P.-M., Mykles, D. L., Schwartz, L. M. (1995) Changes in the structure and function of the multicatalytic proteinase (proteasome) during programmed cell death in the intersegmental muscles of the hawkmoth, Manduca sexta. Dev. Biol. 169, 436-447.

9. Lockshin, R. A. (1969) Programmed cell death. Activation of lysis by a mechanism involving the synthesis of protein. J. Insect Physiol. 15, 1505-1516.

10. Mykles, D. L. (1998) Intracellular proteinases of invertebrates: calcium-dependent and proteasome/ubiquitin-dependent systems. Int. Rev. Cytol. 184, 157-289.

11. Orino, E., Tanaka, K., Tamura, T., Sone, S., Ogura, T., Ichihara, A. (1991) ATP-dependent reversible association of proteasomes with multiple protein components to from $26 \mathrm{~S}$ complexes that degrade ubiquitinated protein in human HL-60 cells. FEBS Lett. 284, 206-210.

12. Orlowski, R. Z. (1999) The role of ubiquitin-proteasome pathway in apoptosis. Cell Death Diff. 6 , 303-313.

13. Samuels, R., Reynolds, S. E. (1993) Moulting fluid enzymes of the tobacco hornworm, Manduca sexta: timing of proteolytic and chitinolytic activity in relation to pre-ecdysial development. Arch. Insect Physiol. Biochem. 24, 33-44.

14. Schwartz, L. M. (1992) Insect muscle as a model for programmed cell death. J. Neurobiol. 23, 1312-1326.

15. Schwartz, L. M., Myer, A., Kosz, L., Engelstein, M., Maier, C. (1990) Activation of polyubiquitin gene expression during developmentally programmed cell death. Neuron 5, 411-419.

16. Schwartz, L. M., Truman, J. W. (1983) Hormonal control of rates of metamorphic development in the tobacco hornworm Manduca sexta. Dev. Biol. 99, 103-114.

17. Takayanagi, K., Dawson, S., Reynolds, S. E., Mayer, R. J. (1996) Specific developmental changes in the regulatory subunits of the $26 \mathrm{~S}$ proteasome in intersegmental muscles preceding eclosion in Manduca sexta. Biochem. Biophys. Res. Com. 228, 517-523.

18. Voges, D., Zwick1, P., Baumeister, W. (1999) The 26S proteasome: A molecular machine designed for controlled proteolysis. Ann. Rev. Biochem. 68, 1015-1068.

19. Zwickl, P., Baumeister, W. (1999) AAA-ATPases at the crossroads of protein life and death. Nature Cell Biology 1, E97-E98. 